\title{
DEVELOPMENT OF A REVISED TAXONOMIC APPROACH FOR IMPROVING SUPPLY CHAIN INTEGRATION AND COLLABORATION
}

\author{
Ping-Kuo CHEN (D) ${ }^{1}$, Yun Yan LUD2* \\ ${ }^{1}$ Business School, Shantou University, Shantou City, China \\ ${ }^{2}$ Department of Human Resource Management, Wenzhou Business College, \\ Wenzhou City, China
}

Received 02 June 2019; accepted 02 March 2020

\begin{abstract}
Although integration and collaboration are considered critical factors in supply chain practice, improving integration and collaboration still encounters a dilemma that is ascribable to three problems, i.e., partners' opportunistic behaviours, the complicated resource distribution and heavy workloads, and large time costs. To solve these problems and effectively improve integration and collaboration, a revised taxonomic approach will be developed in this research. Based on the case of East Asia, the revised taxonomic approach can produce guidelines to help manufacturers well know how to effectively improve integration and collaboration in a sequential manner and avoid encountering the three problems noted above. There are multiple implications of this study; the research results not only develop a new approach by revising theory but also provide convenient tools to help manufacturers effectively improve integration and collaboration when entering different markets. Thus, this study makes great contributions to the field.
\end{abstract}

Keywords: supply chain, integration, taxonomy, competitive performance, collaboration, opportunisitc behaviour.

JEL Classification: D22.

\section{Introduction}

With the rise of globalization and competition, an increasing number of manufacturers are becoming aware that it is difficult to expand their competitiveness and obtain a global market share alone. Therefore, to solve this dilemma, they are cashing off all their preconceived ideas and relinquishing their traditional upstream-downstream transaction relationships with other companies. Instead, a partnership relationship has gradually developed, and a supply chain operational environment has been further established.

\footnotetext{
*Corresponding author. E-mail: Kara_lyy@163.com
} 
A supply chain is defined as a network within an organization or between multiple organizations that involves the procurement of raw materials, the conversion from raw materials to final products, and the distribution of the final products to markets (Wang et al., 2016). Avelar-Sosa et al. (2019) indicated that a supply chain can create a cooperative synergy of manufacturers and partners. Thus, when manufacturers connect with partners to develop a large supply chain operational environment, the competitiveness of the manufacturers is amplified, further improving their competitive advantage as they strive for global market share.

However, Soosay and Hyland (2015) indicated that if it lacks integration and collaboration, the supply chain cannot work the way that it was intended. Supply chain integration is defined as the extent to which all functional activities within an organization and the functional activities of its suppliers, customers and other supply chain partners are linked and integrated together (Sundram et al., 2018). Collaboration is defined as the integration of two or more autonomous partners to plan and execute supply chain functional activities (Nguyen et al., 2019). If there is a lack of integration and collaboration and each manufacturer and partner are just performing their own work, then it will be hard to create a synergy.

Based on the above, improving integration and collaboration is an important task in today's supply chain environment, and researchers have developed a positive approach to improve integration and collaboration. According to related research results, most researchers concur that coordination is the critical method (Mora-Monge et al., 2010). However, the investigative results of Frohlich and Westbrook (2001) and Schoenherr and Swink (2012) show that in the real world, it is difficult to improve integration and collaboration. Many manufacturers continuously improve their coordination; however, it is still difficult for them to successfully improve their integration and collaboration. Why is this the case? This difficulty is ascribable to three problems, i.e., partners' opportunistic behaviours, the complicated resource distribution and heavy workloads, and large time costs.

The first problem is partners' opportunistic behaviours. If all partners agree to improve the integration and collaboration with regard to all functional activities, then the dependent relationship between manufacturers and partners will be enhanced and will form a relationship between profit and risk sharing. However, manufacturers cannot promise integration, and through collaboration, partners can gain greater competitiveness and further obtain larger profits. Conversely, this process may also lead to related risks that cause profit losses. Therefore, Yuen and Thai (2017) indicated that, considering the risks, more partners may exhibit opportunistic behaviours, which may lead to a cessation of integration and collaboration; thus, coordination cannot stop opportunistic behaviour. The second problem is the complicated resource distribution and heavy workloads. Many functional activities require integration and collaboration to improve the process. Chen et al. (2018) indicated that this requirement will lead to complicated resource distributions and workloads if both aspects improve at the same time, and some partners may give up encouraging integration and collaboration due to resource limitations and the heavy workload. The third problem is the large time costs. When manufacturers enter a new market, they need to explore its demands. However, every market has a different order of demand priorities that must be satisfied in a sequential manner. A few demands are basic and function as a market door opener, and these demands are usually linked with market trust (Echave et al., 2006). If manufacturers 
cannot satisfy these basic priority demands, they will find it hard to obtain market trust. In addition, satisfying different demands usually depends on integration and collaboration with regard to different functional activities. Considering the demands of different markets and their satisfactory order of priority demands, manufacturers need to adjust their integration and collaboration with regard to different functional activities (Alblas \& Jayaram, 2015). However, the exploration of these demands and the adjustments needed for integration and collaboration with regard to different functional activities waste a large amount of time. The costs of this loss of time will lead to a risk of profit losses, restlessness among partners and the appearance of opportunistic behaviours.

In existing studies, explorations of how to solve these problems are lacking; however, when organizing these problems, solving the third problem will also solve the other two problems. If manufacturers can well know the demands of different markets, they will be able to judge which demands are basic and decide the satisfactory order of priority demands, which will help them know how to rapidly integrate and collaborate with regard to different functional activities. However, following the satisfactory order of priority demands requires doing so gradually, which means that integration and collaboration should be improved in a sequential manner. If manufacturers can improve integration and collaboration in such a manner, they can avoid causing complicated resource distributions and heavy workloads for their partners. Therefore, the second problem will be solved. In addition, satisfying basic demands will help manufacturers obtain market trust, which will help them to obtain market qualifications (Miltenburg, 2005). Chen et al. (2018) indicated that obtaining market qualifications usually means a steady growth of profit and obtaining market trust. When obtaining market trust, manufacturers will obtain the chance to engage the market, and the market will allow them to further improve their integration and collaboration-based satisfactory order of priority demands, which will ensure their gradual profit expansion. Thus, the process can increase partners' intention to engage in integration and collaboration and decrease the probability of the occurrence of opportunistic behaviour. Therefore, the first problem will be solved.

Based on the above, the third problem is critical. However, how can this problem be solved? To solve the third problem, an effective analysis approach is needed. Such an approach can guide manufacturers in analysing and well knowing the demands of different markets, judging which demands are basic, and deciding the satisfactory order of priority demands. It should also help manufacturers know how to rapidly adjust and improve integration and collaboration with regard to different functional activities in a step-by-step manner when facing different market demands. However, manufacturers still lack an approach for solving the third problem. For this reason, this study will attempt to develop a revised taxonomic approach to help manufacturers solve this problem. To develop the revised taxonomic approach, the traditional taxonomic approach is an important basis.

This article is structured as follows. First, the article will introduce a literature review related to the concept of the traditional taxonomy and its analysis process. In addition, we explain the feasibility of using the traditional taxonomic approach to develop revised taxonomic approaches and explain the revision directions. The second section will address the methodology and will introduce the revised taxonomic approach and explain its analysis 
process. Third, we demonstrate the application of the revised taxonomic approach using the case of East Asia. The results will show how to use the revised taxonomic approach to produce guidelines to guide manufacturers to improve integration and collaboration in a sequential manner. Fourth section discuss the strength of the approach-based results from the case study and compare them with those from existing approaches to improving integration and collaboration. The fifth section provides the conclusion and limitations and highlights the implications of this study and future research directions.

\section{Literature review}

\subsection{Introduction of the traditional taxonomic approach}

The taxonomy concept originated from biology; biologists classify and identify species through a taxonomic approach (Nickerson et al., 2009). However, a taxonomic approach has been gradually implemented by researchers in the fields of business and management, and it has been applied to the classification and development of related strategies. Currently, taxonomy is widely used in every management field.

In the supply chain field, researchers usually adopt a taxonomy to develop related strategies or to identify critical factors. For example, Huo et al. (2019) tried to identify supply chain quality strategies, Cao et al. (2015) developed seven integration competitive patterns, and Sangari et al. (2016) identified the critical successful factors of the practice of supply chain agility through taxonomic analysis. How can related strategies be classified and the critical factors be identified through a taxonomy? According to the experiences of Miller and Roth (1994), Huo et al., Cao et al., and Sangari et al., doing so depends on a three-step analysis process.

The first step consists of defining the observed variables and collecting the sample data. The observed variables should involve the elements of strategy development and critical factor formulation. For example, the development of a green supply chain strategy depends on developing green internal and external activities (Kumar et al., 2015); therefore, researchers should define these green internal and external activities as observed variables. Rakovska and Stratieva (2018) tried to develop health care supply chain strategies based on a taxonomy, and formulating health care supply chain strategies depends on health care activities. Therefore, health care activities are defined as observed variables. After defining the observed variables, the sample data should be collected based on the observed variables.

The second step consists of deciding the number of clusters and classifying the samples into each cluster. In this step, two-stage cluster analysis is adopted. This method covers two parts: the first part is hierarchical cluster analysis, and the second part is K-main analysis. In the first part, hierarchical cluster analysis uses Ward's method to calculate similarities; in addition, it is combined with the squared Euclidean distance to choice as a similarity-difference measure in the calculation of the distance between variables. Finally, an agglomeration schedule table is produced to decide the number of clusters. These clusters can be considered a number of related strategies or critical factors (Chen et al., 2018). In the second part, $\mathrm{K}$-means analysis is used to classify and determine the samples of each cluster. In addition, 
ANOVA is adopted to verify the independence of each cluster. Finally, the sample means and standard errors for the observed variables of each cluster are calculated and ranked.

The third step consists of identifying the related strategies and critical factors based on the mean ranking of the observed variables for each cluster. Different rankings of the observed variables usually have different characteristics. Therefore, researchers usually connect them with the related literature or their own experience and label them based on characteristics so that they become strategies and critical factors. For example, Zhao et al. (2006) tried to identify manufacturing strategies through combinations of indices of low price, design flexibility, volume flexibility, conformance quality, performance quality, speed, dependability, after-sales service, and a broad product line. Therefore, these nine indices seemed to be observed variables. Through two-stage cluster analysis, the authors found four combinations of observed variables and labelled and identified the strategies based on the characteristics of the observed variable combinations of every cluster. Kathuria (2000) argued that the development of manufacturing strategies occurs through combinations of cost, quality, delivery, and flexibility. Thus, Kathuria used a taxonomy to classify these four types of combinations of priorities and to observe their characteristics and links with the related literature to identify four types of strategies.

\subsection{Feasibility and revised directions of the traditional taxonomic approach}

Based on the above, the traditional taxonomic approach in the supply chain field is usually used to classify related strategies or to identify critical factors. However, why do studies believe that this approach can be revised to further become a new approach to improve integration and collaboration?

The analysis results of Kathuria show an example. In the research results of Kathuria (2000), four clusters and label strategy names based on the characteristics of each cluster were obtained. The first cluster was labelled the starter strategy group because the mean of all competitive priority trends was lower. The second cluster was labelled the efficient conformer strategy group because its cost and quality coefficients were prominent. Due to delivery and quality, the third cluster was labelled the speedy conformer strategy group. Thus, with all of the competitive priorities already being highlighted, the fourth cluster was labelled the do all group. However, this study found that a phased improvement phenomenon appeared in Kathuria's analysis results. Specifically, the mean of all competitive priorities in the starter group was on the lower side, even though the mean of quality was slightly. In the efficient conformer strategy group, delivery and flexibility tended to be lower, while cost and quality appeared to be higher. Connecting with the starter group, an efficient conformer strategy group seems to be developed based on quality. Therefore, quality continues to be improved from the starter group to the efficient conformer strategy group, and cost is associated with improvement in the efficient conformer strategy group. Next, in addition to quality, cost is continuously improved from the efficient conformer strategy group to the speedy conformer strategy group, and delivery is associated with improvement. In the do all group, quality, cost, and delivery are continuously improved from the speedy conformer group to the do all group, and delivery is associated with an improvement in the do all group. The above 
seems as a manufacturing strategy development steps. In addition to Kathuria's research, the analysis results of Paulraj et al. (2012), Zhao et al. (2006), and Grant et al. (2013) showed the same phenomena.

Additionally, Kathuria, Zhao et al., Grant et al., and Paulraj et al. explored the relationship between different strategies and operational or financial performance, and they used a taxonomic approach to analyse this performance. The taxonomic analysis results of this performance also appeared to show a phase-achieving phenomenon within the phased strategy development. The mean performance of the first strategy was lower, and only a few types of performance showed outstanding levels. However, the first strategy achieved only a few types of performance, while the mean performance of the second and third strategies was significantly increased; these strategies seemed to achieve higher performance, and the fourth strategy achieves all types of performance. Performance achievement also means that market demand is satisfied (Plott et al., 2019). Based on the above, the phased achievement of performance seems to be a satisfactory order of priority demands. Under the phased achievement process, researchers or practitioners can infer which demands are basic and should be satisfied as a priority, and they can understand how to satisfy these demands in a sequential manner to obtain a competitive advantage. If combined with inferences related to the previous paragraph, researchers or practitioners will know how to achieve these types of performance to gradually satisfy the demands within the phased strategy development.

Based on the above, if the phased development phenomenon can be proven, the traditional taxonomic approach can become a new approach that can be used to explore improving integration and collaboration in a sequential manner. However, there is still a problem. That is, a method to prove the phased improvement phenomenon is still lacking. If the above phenomenon cannot be proven, it will be difficult to explore improving integration and collaboration in a sequential manner. Of course, it is also difficult to judge which performance should be achieved in the different steps of strategy development. Accordingly, when this study uses the traditional taxonomic approach, it is still difficult to produce a positive effect on integration and collaboration and to understand how to improve them in a sequential manner. However, if the lack of a traditional taxonomic approach can be compensated for through related statistical methods, it will be possible for the this approach to become a new approach that can be used to explore improving integration and collaboration. Therefore, we try to prove the phased improvement through related statistical methods that are mainly revised directions.

\section{Methodology}

Based on the literature review, this section will develop a revised taxonomic approach. In this research, correlation analysis and within-cluster paired-sample t-tests will be added to compensate for the lack of a traditional taxonomic approach in proving phased improvement phenomena. Based on the addition of these two methods, this study further develops a revised taxonomic analysis process. The analysis process has five steps, and this section will explain them as follows. 
Step 1: As a traditional taxonomic approach, this step first defines the observed variables. The revised taxonomic approach is applied to guide manufacturers to analyse and well know the demands of different markets, to judge which demands are basic, to decide the satisfactory order of priority demands and to further help manufacturers know how to rapidly adjust integration and collaboration with regard to different functional activities when facing different market demands and to well know how to improve their integration and collaboration in a sequential manner. Therefore, the observed variables for integration and collaboration and demand should be defined. According to the introduction, "integration and collaboration" means that the functional activities of manufacturers and partners are linked, planned, and executed jointly. Therefore, these functional activities will be defined as observed variables. Regarding demand, consider the relationship between competitive performance and demand satisfaction; therefore, competitive performance will replace demand as the observed variable. Then, based on these observed variables, in this step, related data should be collected. Regarding data collection, it is preferable for manufacturers to collect information on competitors' experiences in jointly linking, planning, and executing functional activities and competitive performance based on different markets. When the data collection is complete, the normality of the data should be tested in this step.

Step 2: Use two-stage cluster analysis to determine the number of improvement stages of integration and collaboration. As with a traditional taxonomic approach, in this step hierarchical cluster analysis should be used to determine the number of clusters based on the data on functional activities. In addition, K-means analysis will be used to classify the samples. According to the K-means analysis results, all samples will be classified into different clusters. Finally, ANOVA will be adopted to test the independence of each cluster.

Step 3: Based on the analysis results of step 2, the means of the functional activities and competitive performance for each cluster need to be calculated and ranked. Based on the ranking results, the initial phased improvement of functional activities between clusters can be carried out based on a simple observation. Of course, the order of achievement priorities with regard to competitive performance between clusters can also be inferred. In the traditional taxonomic approach, this step will label clusters based on the highest means of the observed variables. In line with the rule of the traditional taxonomic approach, this step will be revised. In this step, correlation analysis will be adopted to analyse the associated relationship. That is, if the mean of functional activity $\mathrm{A}$ is the highest, then the improvement of functional activity B may be associated with that of functional activity A. However, when functional activity $\mathrm{B}$ is improved, it is possible to improve functional activity $\mathrm{C}$. This presents an associated relationship. However, why should such a relationship between the functional activities of each cluster be explored? If only a few functional activities have an associated relationship in the first cluster, an associated relationship exists between more functional activities in the next cluster, and an associated relationship exists between all functional activities in the final cluster, this result may suggest that phased improvement exists in the clusters. Similarly, in this step, through analysis of the associated relationships, the basic types of competitive performance and the order of achievement priorities with regard to competitive performance can be inferred. The concept of step 3 is shown in Figure 1. 


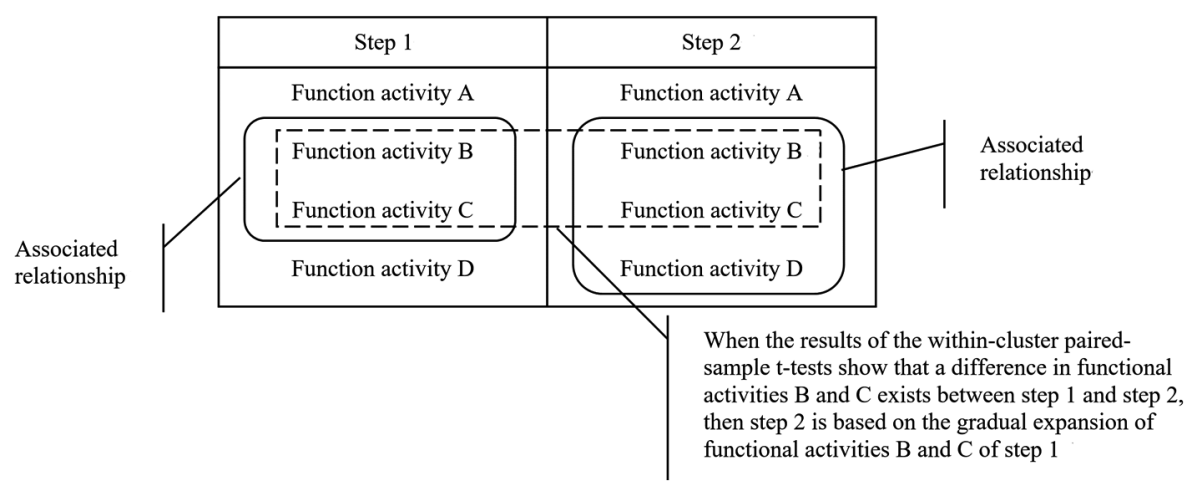

Figure 1. Concept of steps 3 and 4

Step 4: Try to prove that phased improvement exists in the clusters. Although the results of step 3 make it possible to infer that phased improvement may exist in the clusters, this step still needs a statistical method to prove that phased improvement exists. If it can be proven that phased improvement exists in the clusters, then this result may help practitioners well know how to improve integration and collaboration in a sequential manner. With the stepby-step improvement of integration and collaboration, we can well know which competitive performance is basic and thus needs to be achieved in the first step, and we can understand the order of achievement priorities with regard to competitive performance. With the scope of the improvement of integration and collaboration gradually expanding, competitive performance will also be gradually achieved. Based on the above, within-cluster paired-sample t-tests will be adopted. How can phased improvement between clusters be proven through within-cluster paired-sample t-tests? This can be explained using Figure 1. Suppose that integration and collaboration need to improve through two steps, as shown in Figure 1. When testing the associated relationship for step 1 through correlation analysis, suppose that an associated relationship exists between functional activities B and C. The test results of the associated relationship in step 2 show that an associated relationship exists between functional activities B, C, and D. Based on the initial observation, functional activities B and C between the two steps seem to overlap. If the test results of the within-cluster paired-sample t-tests verify the difference between functional activities B and C between the two steps, we can say that step 1 focuses on the improvement of functional activities $B$ and $C$ and that step 2 will continue to improve functional activities $\mathrm{B}$ and $\mathrm{C}$ and drive the improvement of functional activity D. Therefore, phased improvement will be proven to exist. Of course, if the analysis of competitive performance adopts the same method, the analysis results will show which types of competitive performance are basic and should be achieved in step 1. Next, it can show the order of achievement priorities with regard to competitive performance.

Step 5: Based on the results of step 4, the integration and collaboration improvement process will be established. In addition, this step will understand which types of competitive performance are basic and need to be achieved through the integration and collaboration of which functional activities in step 1. With the scope of integration and collaboration gradually expanding in the following steps, it is possible to indicate which types of competitive 
performance will be achieved gradually and on which functional activities the achievement of integration and collaboration will be based. Considering the relationship between competitive performance and market demands, this step needs to further explain how market demands are gradually satisfied through the step-by-step improvement of integration and collaboration.

\section{Case analysis}

\subsection{Observation variables and data collection}

Step 1 of the revised taxonomic approach indicated that the improvement of integration and collaboration depends on the joint linking, planning, and execution of functional activities from manufacturers and partners. Therefore, the improvement levels of functional activities related to linking, planning, and execution are the main observed variables. In addition, to identify which demands are basic and to understand the satisfactory order of priority demands, market demands should be observed variables. However, the relationship between demand satisfaction and competitive performance achievement exists. Therefore, the types of competitive performance can be replaced and become additional observed variables to measure demands. Therefore, the observed variables of these two cases will adopt functional activities and competitive performance.

Regarding the observed variables for functional activities, according to related studies, these can be divided into five types. The first type is sharing information, which involves material demands and the intermediate products of suppliers (Zhao et al., 2001; Shin \& Lee, 2015), production planning, inventory, and downstream market sales (Liu et al., 2015). The second is planning a collaborative approach. To plan appropriate approaches, such as risk/revenue sharing, long-term agreements to maintain the relationship between partners upstream and downstream should be reached (Barratt, 2004). The third type is joint decision making regarding product design/modifications, process design/modifications, quality improvement and cost control between manufacturers and partners both upstream and downstream (McLaren et al., 2002). Designing system coupling is the fourth type of functional activity. System coupling is a coordinating physical activity that takes place through mechanisms such as VMI, CPFR or JIT-Kanban. These are important methods for maintaining stable supply chain integration and collaboration, and manufacturers should join with partners upstream and downstream (Ye et al., 2008). The fifth type is developing an international upstream source strategy and a downstream distribution network. A source strategy is used to expand relationships with upstream partners (Bai \& Gao, 2017), and a distribution strategy aims to optimize relationships with downstream partners and even customers (Schlegelmilch, 2016).

Regarding the observed variables for competitive performance, according to the suggestions of related researchers such as Edmunds (2015) and Lee et al. (2018), practitioners usually adopt cost, quality, delivery, and flexibility to measure competitive performance. In fact, there is unanimity with regard to the use of these four competitive performance indices for measuring competitive performance, and they have been widely adopted (Dowlatshahi \& 
Taham, 2009; Prajogo et al., 2016). Regarding cost, Niu et al. (2017) indicated that the unit manufacturing cost and the ordering cost are involved in the quality of product manufacturing, the quality of any assistant resource in the production manufacturing process, and the customer service quality of timely product supply (Boer \& Boer, 2019). In addition to the order delivery speed and reliability, manufacturing and purchasing lead times are involved in delivery (Oh et al., 2016; Tavana et al., 2019). However, flexibility involves the order production mix and volume (Huo et al., 2018), while customization capability is also considered an aspect of flexibility (Kasemsap, 2016).

Next, based on the observed variables, this research collects related data. However, to increase the efficiency of data collection, this study will adopt data from the International Manufacturing Strategy Survey (IMSS), a global research platform. Through 2020, 22 teams from different economies will have joined the cooperative research network. The aim of the IMSS is to survey global manufacturers' practices and performance, the strategies and performance of manufacturing as a plant's dominant activity, and current manufacturing and supply chain practices. To achieve its aim, the IMSS reviews related research results, conducts interviews with practitioners and develops a Likert scale questionnaire. The questionnaire covers questions from every field of manufacturing and supply chain practice, at least as much as possible; therefore, it is a large questionnaire. To ensure the reliability of the questionnaire, a pretest was necessary when finishing the design of the questionnaire. Next, the questionnaire was revised based on the pretest results and distributed to members. Every member must distribute the questionnaire to representative manufacturers in their own industry, and the number of samples should exceed 30. When finishing the data collection, the IMSS further checks sample validity, deleting ineffective or outlier samples. Finally, every member can select related data based on the research direction they wish to test. Although the IMSS provides secondary data, because the questionnaire was designed to cover questions from every field in manufacturing and supply chains, IMSS data have been adopted in recent years, with more than 500 papers since 2009 having used IMSS data to test their research questions.

Based on the observed variables, this study tried to compare the content of the IMSS questionnaire. Based on the comparative results, the IMSS questionnaire investigated the "jointly improved level of functional activities between manufacturers, suppliers, and customers" and used five items, as shown in Table 1. The items of the IMSS match the definitions of the observed variables for the improvement of the functional activities of the supply chain; therefore, it is appropriate for this research to use the IMSS data for analysis. Regarding competitive performance, the IMSS designed 12 items, as shown in Table 2, to investigate the "achieved level of manufacturers' competitive performance". The items of the IMSS correspond with the definitions of the observed variables for competitive performance; therefore, it is also appropriate to adopt IMSS data on competitive performance for research analysis.

In this research, the case of East Asia will be adopted to demonstrate how to use the revised taxonomic approach to analyse how to improve integration and collaboration in a sequential manner when entering the East Asian market. Therefore, in this research, 149 samples from East Asia from the IMSS are adopted; 49 samples are from China, 74 samples are from Japan, and 26 samples are from Taiwan. According to step 1 of the revised taxo- 
nomic approach, the normality of the data on functional activities and competitive performance must be tested by five indices. The test results are shown in Tables 3 and 4, and all data satisfy the requirements of normality.

Table 1. Variables of functional activities

\begin{tabular}{|l|l|}
\hline & \multicolumn{1}{c|}{ Variable items of functional activities } \\
\hline \multirow{4}{*}{$\begin{array}{l}\text { Past improvement level with } \\
\text { supplier } \\
1=\text { none, } 5=\text { high level }\end{array}$} & S1. Sharing information with key suppliers \\
\cline { 2 - 2 } & S2. Developing collaborative approaches with key suppliers \\
\cline { 2 - 2 } & S3. Joint decision making with key suppliers \\
\cline { 2 - 2 } & S4. System coupling with key suppliers \\
\cline { 2 - 2 } & S5. Developing an international sourcing strategy \\
\hline \multirow{4}{*}{$\begin{array}{l}\text { Past improvement level with } \\
\text { customer: }\end{array}=$ none, $5=$ high level } & R1. Sharing information with key customers \\
\cline { 2 - 2 } & R2. Developing collaborative approaches with key customers \\
\cline { 2 - 2 } & R3. Joint decision making with key customers \\
\cline { 2 - 2 } & R4. System coupling with key customers \\
\cline { 2 - 2 } & R5. Developing an international distribution strategy \\
\hline
\end{tabular}

Table 2. Variables of competitive performances

\begin{tabular}{|c|c|}
\hline & $\begin{array}{l}\text { Variable items of competitive } \\
\text { performances }\end{array}$ \\
\hline \multirow{2}{*}{$\begin{array}{l}\text { Compared to past cost improvement effort the indicator } \\
\text { has: } 1=\text { Decrease, } 2=\text { stayed about the same, } 3=\text { slightly } \\
\text { increased, } 4=\text { increased, } 5=\text { Strongly increased }\end{array}$} & C1. Unit manufacturing cost \\
\hline & C2. Ordering costs \\
\hline \multirow{3}{*}{$\begin{array}{l}\text { Compared to past quality improvement effort the indicator } \\
\text { has: } 1=\text { Decrease, } 2=\text { stayed about the same, } 3=\text { slightly } \\
\text { increased, } 4=\text { increased, } 5=\text { Strongly increased }\end{array}$} & Q1. Product quality and reliability \\
\hline & Q2. Conformance quality \\
\hline & Q3. Customer service quality \\
\hline \multirow{4}{*}{$\begin{array}{l}\text { Compared to past delivery improvement effort the indicator } \\
\text { has: } 1=\text { Decrease, } 2=\text { stayed about the same, } 3=\text { slightly } \\
\text { increased, } 4=\text { increased, } 5=\text { Strongly increased }\end{array}$} & E1. Delivery speed \\
\hline & E2. Delivery reliability \\
\hline & E3. Manufacturing lead time \\
\hline & E4. Procurement lead time \\
\hline \multirow{3}{*}{$\begin{array}{l}\text { Compared to past flexibility improvement effort the indicator } \\
\text { has: } 1=\text { Decrease, } 2=\text { stayed about the same, } 3=\text { slightly } \\
\text { increased, } 4=\text { increased, } 5=\text { Strongly increased }\end{array}$} & L1. Volume flexibility \\
\hline & L2. Mix flexibility \\
\hline & L3. Product customization \\
\hline
\end{tabular}

Table 3. Results of normality (functional activities)

\begin{tabular}{|c|c|c|c|c|c|}
\hline Items & Mean & Std. Deviation & Variance & Skewness & Kurtosis \\
\hline S1. & 3.4362 & 0.95381 & 0.910 & -0.312 & -0.197 \\
\hline S2. & 3.3557 & 0.88588 & 0.785 & -0.115 & 0.240 \\
\hline S3. & 3.3490 & 0.81312 & 0.661 & -0.188 & 0.462 \\
\hline S4. & 3.1879 & 0.99573 & 0.991 & -0.303 & -0.073 \\
\hline
\end{tabular}


End of Table 3

\begin{tabular}{|c|c|c|c|c|c|}
\hline Items & Mean & Std. Deviation & Variance & Skewness & Kurtosis \\
\hline S5. & 3.1745 & 1.07006 & 1.145 & -0.456 & -0.379 \\
\hline R1. & 3.4228 & 0.93852 & 0.881 & -0.345 & 0.083 \\
\hline R2. & 3.2550 & 0.93110 & 0.867 & -0.277 & -0.023 \\
\hline R3. & 3.3356 & 0.88996 & 0.792 & -0.541 & 0.388 \\
\hline R4. & 3.2953 & 0.96214 & 0.926 & -0.486 & 0.057 \\
\hline R5. & 3.1074 & 1.02100 & 1.042 & -0.334 & -0.034 \\
\hline
\end{tabular}

Table 4. Results of normality (competitive performances)

\begin{tabular}{|c|c|c|c|c|c|}
\hline Items & Mean & Std. Deviation & Variance & Skewness & Kurtosis \\
\hline C1. & 2.4094 & 0.86222 & 0.743 & 0.701 & 0.868 \\
\hline C2. & 2.4832 & 0.84313 & 0.711 & 0.396 & 0.467 \\
\hline Q3. & 2.8725 & 0.86437 & 0.747 & 0.441 & -0.145 \\
\hline Q4. & 2.7718 & 0.86306 & 0.745 & 0.652 & 0.071 \\
\hline Q5. & 2.7987 & 0.89276 & 0.797 & 0.871 & 0.127 \\
\hline E1. & 2.8523 & 0.88818 & 0.789 & 0.412 & -0.240 \\
\hline E2. & 2.8523 & 0.88054 & 0.775 & 0.595 & 0.098 \\
\hline E3. & 2.6174 & 0.82689 & 0.684 & 0.454 & 0.254 \\
\hline E4. & 2.5436 & 0.79256 & 0.628 & 0.515 & 0.749 \\
\hline L1. & 2.7315 & 0.87480 & 0.765 & 0.676 & 0.125 \\
\hline L2. & 2.7651 & 0.80865 & 0.654 & 0.610 & 0.045 \\
\hline L3. & 2.7517 & 0.91464 & 0.837 & 0.515 & -0.410 \\
\hline
\end{tabular}

\subsection{Analysis results}

This section will demonstrate the analysis using the revised taxonomic approach from step 2 to step 5. In step 2 of the revised taxonomic approach, five clusters are classified through hierarchical cluster analysis. This means that manufacturers need to improve their integration and collaboration in five stages when they try to enter the East Asian market. Next, this study further classifies the samples into each stage through K-means analysis and conducts ANOVA to test the independence of each stage. The analysis results indicate that significant differences between the stages are supported. In step 3, we use the samples of each cluster, further calculate the means of the observed variables (including standard errors) and rank these variables based on their means. The mean of stage 1 must be lower, and the means will gradually increase through the following stages. In the final stage, the mean will achieve its highest level. The above phenomenon appears in the analysis of functional activities and competitive performance. Therefore, phased improvement between the stages exists. Tables $5 \mathrm{a}$ and $5 \mathrm{~b}$ show the analysis results from step 2 to step 3. 
Table 5a. Analysis results of functional activities

\begin{tabular}{|c|c|c|c|c|c|c|c|}
\hline & & $\begin{array}{l}\text { Stage } 1 \\
(\mathrm{n}=8)\end{array}$ & $\begin{array}{l}\text { Stage } 2 \\
(\mathrm{n}=25)\end{array}$ & $\begin{array}{l}\text { Stage } 3 \\
(\mathrm{n}=61)\end{array}$ & $\begin{array}{l}\text { Stage } 4 \\
(\mathrm{n}=36)\end{array}$ & $\begin{array}{l}\text { Stage } 5 \\
(\mathrm{n}=19)\end{array}$ & F-value \\
\hline \multirow{3}{*}{ S1 } & Mean & $2.500^{(4,5)}$ & $2.920^{(4,5)}$ & $3.148^{(4,5)}$ & $3.972^{(1,2,3)}$ & $4.421^{(1,2,3)}$ & \multirow{3}{*}{$19.641^{* *}$} \\
\hline & S.E. & 0.655 & 0.152 & 0.099 & 0.049 & 0.176 & \\
\hline & Rank & 1 & 1 & 6 & 3 & 3 & \\
\hline \multirow{3}{*}{ S2 } & Mean & $2.000^{(3,4,5)}$ & $2.600^{(3,4,5)}$ & $3.115^{(1,2,4,5)}$ & $4.000^{(1,2,3)}$ & $4.473^{(1,2,3)}$ & \multirow{3}{*}{$57.056^{* *}$} \\
\hline & S.E. & 0.423 & 0.141 & 0.047 & 0.056 & 0.177 & \\
\hline & Rank & 4 & 3 & 7 & 2 & 2 & \\
\hline \multirow{3}{*}{ S3 } & Mean & $2.250^{(3,4,5)}$ & $2.680^{(3,4,5)}$ & $3.164^{(1,2,4,5)}$ & $3.917^{(1,2,3)}$ & $4.211^{(1,2,3)}$ & \multirow{3}{*}{$35.587^{* *}$} \\
\hline & S.E. & 0.412 & 0.138 & 0.058 & 0.047 & 0.196 & \\
\hline & Rank & 3 & 2 & 5 & 5 & 7 & \\
\hline \multirow{3}{*}{ S4 } & Mean & $1.125^{(2,3,4,5)}$ & $2.360^{(1,3,4,5)}$ & $3.049^{(1,2,4,5)}$ & $3.889^{(1,2,3)}$ & $4.263^{(1,2,3)}$ & \multirow{3}{*}{$60.526^{* *}$} \\
\hline & S.E. & 0.125 & 0.114 & 0.072 & 0.053 & 0.263 & \\
\hline & Rank & 6 & 7 & 9 & 6 & 5 & \\
\hline \multirow{3}{*}{ S5 } & Mean & $1.000^{(2,3,4,5)}$ & $2.360^{(1,3,4,5)}$ & $3.213^{(1,2,5)}$ & $3.722^{(1,2)}$ & $4.000^{(1,2,3)}$ & \multirow{3}{*}{$30.885^{* *}$} \\
\hline & S.E. & 0.000 & 0.151 & 0.081 & 0.130 & 0.306 & \\
\hline & Rank & 9 & 7 & 3 & 10 & 9 & \\
\hline \multirow{3}{*}{$\mathrm{R} 1$} & Mean & $2.125^{(3,4,5)}$ & $2.560^{(3,4,5)}$ & $3.300^{(1,2,4,5)}$ & $3.833^{(1,2,3,5)}$ & $4.737^{(1,2,3,4)}$ & \multirow{3}{*}{$44.350^{* *}$} \\
\hline & S.E. & 0.639 & 0.130 & 0.063 & 0.063 & 0.129 & \\
\hline & Rank & 2 & 5 & 1 & 7 & 1 & \\
\hline \multirow{3}{*}{$\mathrm{R} 2$} & Mean & $2.000^{(3,4,5)}$ & $2.240^{(3,4,5)}$ & $3.131^{(1,2,4,5)}$ & $3.833^{(1,2,3,5)}$ & $4.421^{(1,2,3,4)}$ & \multirow{3}{*}{$54.319^{\star *}$} \\
\hline & S.E. & 0.655 & 0.105 & 0.044 & 0.075 & 0.139 & \\
\hline & Rank & 4 & 10 & 8 & 7 & 3 & \\
\hline \multirow{3}{*}{ R3 } & Mean & $1.250^{(2,3,4,5)}$ & $2.560^{(1,3,4,5)}$ & $3.230^{(1,2,4,5)}$ & $4.028^{(1,2,3)}$ & $4.263^{(1,2,3)}$ & \multirow{3}{*}{$91.479^{* *}$} \\
\hline & S.E. & 0.164 & 0.130 & 0.054 & 0.028 & 0.168 & \\
\hline & Rank & 6 & 5 & 2 & 1 & 5 & \\
\hline \multirow{3}{*}{$\mathrm{R} 4$} & Mean & $1.125^{(2,3,4,5)}$ & $2.600^{(1,3,4,5)}$ & $3.197^{(1,2,4,5)}$ & $3.944^{(1,2,3)}$ & $4.211^{(1,2,3)}$ & \multirow{3}{*}{$52.771^{* *}$} \\
\hline & S.E. & 0.125 & 0.153 & 0.069 & 0.056 & 0.237 & \\
\hline & Rank & 6 & 3 & 4 & 4 & 7 & \\
\hline \multirow{3}{*}{ R5 } & Mean & $1.000^{(2,3,4,5)}$ & $2.360^{(1,3,4,5)}$ & $3.049(1,2,4,5)$ & $3.778^{(1,2,3)}$ & $3.895^{(1,2,3)}$ & \multirow{3}{*}{$36.486^{* *}$} \\
\hline & S.E. & 0.000 & 0.162 & 0.049 & 0.113 & 0.323 & \\
\hline & Rank & 9 & 7 & 9 & 9 & 10 & \\
\hline
\end{tabular}


Table 5b. Analysis results of competitive performances

\begin{tabular}{|c|c|c|c|c|c|c|c|}
\hline & & $\begin{array}{l}\text { Stage } 1 \\
(\mathrm{n}=8)\end{array}$ & $\begin{array}{l}\text { Stage } 2 \\
(\mathrm{n}=25)\end{array}$ & $\begin{array}{l}\text { Stage } 3 \\
(\mathrm{n}=61)\end{array}$ & $\begin{array}{l}\text { Stage } 4 \\
(\mathrm{n}=36)\end{array}$ & $\begin{array}{l}\text { Stage } 5 \\
(\mathrm{n}=19)\end{array}$ & F-value \\
\hline \multirow{3}{*}{$\mathrm{C} 1$} & Mean & $1.750^{(4,5)}$ & $2.160^{(4)}$ & $2.197^{(4,5)}$ & $2.833^{(1,2,3)}$ & $2.895^{(1,3)}$ & \multirow{3}{*}{$7.389^{* *}$} \\
\hline & S.E. & 0.163 & 0.149 & 0.080 & 0.152 & 0.264 & \\
\hline & Rank & 11 & 11 & 12 & 12 & 10 & \\
\hline \multirow{3}{*}{$\mathrm{C} 2$} & Mean & 2.000 & $2.000^{(4)}$ & 2.426 & $2.917^{(2)}$ & 2.684 & \multirow{3}{*}{$6.189^{* *}$} \\
\hline & S.E. & 0.267 & 0.153 & 0.086 & 0.140 & 0.242 & \\
\hline & Rank & 4 & 12 & 10 & 9 & 12 & \\
\hline \multirow{3}{*}{ Q1 } & Mean & $2.205^{(4,5)}$ & $2.600^{(4,5)}$ & $2.672^{(4,5)}$ & $3.278^{(1,2,3)}$ & $3.368^{(1,2,3)}$ & \multirow{3}{*}{$6.996^{* *}$} \\
\hline & S.E. & 0.366 & 0.129 & 0.090 & 0.157 & 0.205 & \\
\hline & Rank & 2 & 3 & 4 & 1 & 2 & \\
\hline \multirow{3}{*}{ Q2 } & Mean & $2.125^{(5)}$ & 2.640 & $2.590^{(5)}$ & 3.028 & $3.316^{(1,3)}$ & \multirow{3}{*}{$5.141^{* *}$} \\
\hline & S.E. & 0.227 & 0.151 & 0.092 & 0.162 & 0.217 & \\
\hline & Rank & 3 & 1 & 6 & 8 & 4 & \\
\hline \multirow{3}{*}{ Q3 } & Mean & $2.250^{(5)}$ & $2.480^{(4,5)}$ & $2.574^{(4,5)}$ & $3.222^{(2,3)}$ & $3.368^{(1,2,3)}$ & \multirow{3}{*}{$7.643^{* *}$} \\
\hline & S.E. & 0.313 & 0.117 & 0.095 & 0.144 & 0.267 & \\
\hline & Rank & 1 & 6 & 8 & 2 & 2 & \\
\hline \multirow{3}{*}{ E1 } & Mean & $2.000^{(4)}$ & 2.640 & 2.787 & $3.167^{(1)}$ & 3.105 & \multirow{3}{*}{$4.114^{* *}$} \\
\hline & S.E. & 0.189 & 0.151 & 0.107 & 0.141 & 0.252 & \\
\hline & Rank & 4 & 1 & 1 & 4 & 7 & \\
\hline \multirow{3}{*}{ E2 } & Mean & $2.125^{(4,5)}$ & 2.560 & 2.721 & $3.222^{(1)}$ & $3.263^{(1)}$ & \multirow{3}{*}{$5.642^{* *}$} \\
\hline & S.E. & 0.125 & 0.142 & 0.100 & 0.133 & 0.285 & \\
\hline & Rank & 3 & 4 & 2 & 2 & 5 & \\
\hline \multirow{3}{*}{ E3 } & Mean & 2.000 & 2.440 & 2.590 & 2.861 & 2.737 & \multirow{3}{*}{2.386} \\
\hline & S.E. & 0.267 & 0.192 & 0.092 & 0.133 & 0.214 & \\
\hline & Rank & 4 & 8 & 6 & 11 & 11 & \\
\hline \multirow{3}{*}{$\mathrm{E} 4$} & Mean & $1.875^{(4)}$ & 2.320 & $2.393^{(4)}$ & $2.889^{(1,3)}$ & $2.947^{(1)}$ & \multirow{3}{*}{$6.164^{* *}$} \\
\hline & S.E. & 0.295 & 0.170 & 0.079 & 0.118 & 0.223 & \\
\hline & Rank & 10 & 10 & 11 & 10 & 9 & \\
\hline \multirow{3}{*}{$\mathrm{L} 1$} & Mean & $1.750^{(4,5)}$ & $2.480^{(5)}$ & $2.524^{(4,5)}$ & $3.083^{(1,3)}$ & $3.474^{(1,2,3)}$ & \multirow{3}{*}{$11.171^{* *}$} \\
\hline & S.E. & 0.164 & 0.131 & 0.083 & 0.151 & 0.246 & \\
\hline & Rank & 11 & 6 & 9 & 6 & 1 & \\
\hline \multirow{3}{*}{$\mathrm{L} 2$} & Mean & $2.000^{(4,5)}$ & 2.560 & 2.623 & $3.083^{(1)}$ & $3.211^{(1)}$ & \multirow{3}{*}{$6.284^{* *}$} \\
\hline & S.E. & 0.189 & 0.164 & 0.082 & 0.122 & 0.249 & \\
\hline & Rank & 4 & 4 & 5 & 6 & 6 & \\
\hline \multirow{3}{*}{ L3 } & Mean & $2.000^{(4)}$ & $2.360^{(4)}$ & 2.689 & $3.111^{(1,2)}$ & 3.105 & \multirow{3}{*}{$5.199^{* *}$} \\
\hline & S.E. & 0.189 & 0.162 & 0.106 & 0.158 & 0.228 & \\
\hline & Rank & 4 & 9 & 3 & 5 & 7 & \\
\hline
\end{tabular}


Although phased improvement seems to exist, this finding needs to be further proven. According to the revised taxonomic approach, this study first adopts correlation analysis to explore the associated relationships of the functional activities and competitive performance of each stage. For the functional activities, the analysis results indicated that although S1 ranks the highest in stage 1, it has no associated relationship with other functional activities. In stage 2, an associated relationship between S1, S2, and S3 exists. In stage 3, an associated relationship between S1, S2, S3, R1, R2, R3, and R4 exists. In stages 4 and 5, an associated relationship exists between all functional activities. Regarding competitive performance, Q3 of stage 1 ranks the highest; however, it is not associated with other types of competitive performance. In stage 2, an associated relationship between Q2, Q3, E1, E2, and L2 exists. Regarding stage 3, an associated relationship between E1, E2, E3, Q1, Q2, Q3, L1, L2, and L3 is proven to exist. In stages 4 and 5, an associated relationship exists between all types of competitive performance.

Based on the above, $\mathrm{S} 1$ seems to be the basic functional activity for improving integration and collaboration. In stage 2, the integration and collaboration of S1, S2 and S3 are improved. However, the further improvement of S2 and S3 seems to be based on S1. In stage 3, S1, S2, and S3 become the basis and further expand the scope of integration and collaboration to R1, R2, R3, and R4. Stage 4 seems to further improve the integration and collaboration of all functional activities based on the 7 functional activities of stage 3. Finally, the integration and collaboration of all functional activities appear to be profoundly improved based on stage 4. Regarding competitive performance, in stage 1, Q3 seems to be the basic competitive performance. In stage 2, Q3 seems to expand the competitive performance of Q2, E1, E2, and L2. In stage 3, the expansion of Q1, E3, and L1 is based on Q2, Q3, E1, E2, and L2. Based on the competitive performance of stage 3, all types of competitive performance will be achieved in stage 4 . Thus, the final stage seems to increase the achievement level of all types of competitive performance.

To prove the above inference, within-cluster paired-sample t-tests are adopted in analysis step 4. According to the test results, for the functional activities, the significant difference between $S 1$ of stage 1 and S1 of stage 2 is supported, the significant difference between S1, S2, and S3 of stage 2 and those of stage 3 is supported, the significant difference between S1, S2, S3, R1, R2, R3, and R4 of stage 3 and those of stage 4 is supported, and the significant difference between all functional activities of stage 4 and those of stage 5 is supported. For competitive performance, the significant difference between Q3 of stage 1 and Q3 of stage 2 is supported, the significant difference between Q2, Q3, E1, E2, and L2 of stage 2 and those of stage 3 is supported, the significant difference between E1, E2, E3, Q1, Q2, Q3, L1, L2, and L3 of stage 3 and those of stage 4 is supported, and the significant difference between all types of competitive performance of stage 4 and those of stage 5 is supported. A summary of the analysis results is shown in Table 6.

In step 5 of the revised taxonomic approach, this study gives the conclusion of the analysis results. According to Table 6, to improve integration and collaboration in East Asia, manufacturers should improve through five stages. First, the analysis results show that Q3 (customer service quality) is a basic type of competitive performance and should be achieved as a priority. This also means that customer service satisfaction is a basic demand in East Asia. 
In fact, this analysis result is true. According to the definition of the observed variables, customer service quality means that the product will be rapidly obtained. In East Asia, customers usually express interest in new products. If manufacturers try to implement new products and quickly distribute them to customers, this forms a positive image of the manufacturers. Customers in East Asia will thus agree with the manufacturers' market qualifications. To achieve competitive performance, the analysis results suggest that manufacturers should improve the integration and collaboration of S1, which means sharing information with key suppliers. This result makes sense because the raw material supply will affect the final product supply. Thus, great integration and collaboration with regard to sharing information with suppliers certainly affect customer service quality. When achieving customer service quality, customer trust will increase, and manufacturers will obtain market qualifications. In stage 2, to continue to improve customer service quality, manufacturers need to further improve their competitive performance of Q2 (conformance quality), E1 (delivery speed), E2 (delivery reliability), and L2 (mix flexibility). These factors seem to improve manufacturing

Table 6. Analysis results of the revised taxonomy approach

\begin{tabular}{|c|c|c|c|c|c|}
\hline & Stage 1 & Stage 2 & Stage 3 & Stage 4 & Stage 5 \\
\hline \multicolumn{6}{|c|}{ Functional activities } \\
\hline S1 & $\sqrt{ }$ & $\sqrt{ }$ & $\sqrt{ }$ & $\sqrt{ }$ & $\sqrt{ }$ \\
\hline S2 & & $\sqrt{ }$ & $\sqrt{ }$ & $\sqrt{ }$ & $\sqrt{ }$ \\
\hline S3 & & $\sqrt{ }$ & $\sqrt{ }$ & $\sqrt{ }$ & $\sqrt{ }$ \\
\hline S4 & & & & $\sqrt{ }$ & $\sqrt{ }$ \\
\hline S5 & & & & $\sqrt{ }$ & $\sqrt{ }$ \\
\hline R1 & & & $\sqrt{ }$ & $\sqrt{ }$ & $\sqrt{ }$ \\
\hline R2 & & & $\sqrt{ }$ & $\sqrt{ }$ & $\sqrt{ }$ \\
\hline R3 & & & $\sqrt{ }$ & $\sqrt{ }$ & $\sqrt{ }$ \\
\hline $\mathrm{R} 4$ & & & $\sqrt{ }$ & $\sqrt{ }$ & $\sqrt{ }$ \\
\hline R5 & & & & $\sqrt{ }$ & $\sqrt{ }$ \\
\hline \multicolumn{6}{|c|}{ Competitive performances } \\
\hline $\mathrm{C} 1$ & & & & $\sqrt{ }$ & $\sqrt{ }$ \\
\hline $\mathrm{C} 2$ & & & & $\sqrt{ }$ & $\sqrt{ }$ \\
\hline Q1 & & & $\sqrt{ }$ & $\sqrt{ }$ & $\sqrt{ }$ \\
\hline Q2 & & $\sqrt{ }$ & $\sqrt{ }$ & $\sqrt{ }$ & $\sqrt{ }$ \\
\hline Q3 & $\sqrt{ }$ & $\sqrt{ }$ & $\sqrt{ }$ & $\sqrt{ }$ & $\sqrt{ }$ \\
\hline E1 & & $\sqrt{ }$ & $\sqrt{ }$ & $\sqrt{ }$ & $\sqrt{ }$ \\
\hline E2 & & $\sqrt{ }$ & $\sqrt{ }$ & $\sqrt{ }$ & $\sqrt{ }$ \\
\hline E3 & & & $\sqrt{ }$ & $\sqrt{ }$ & $\sqrt{ }$ \\
\hline $\mathrm{E} 4$ & & & & $\sqrt{ }$ & $\sqrt{ }$ \\
\hline $\mathrm{L} 1$ & & & $\sqrt{ }$ & $\sqrt{ }$ & $\sqrt{ }$ \\
\hline $\mathrm{L} 2$ & & $\sqrt{ }$ & $\sqrt{ }$ & $\sqrt{ }$ & $\sqrt{ }$ \\
\hline L3 & & & $\sqrt{ }$ & $\sqrt{ }$ & $\sqrt{ }$ \\
\hline
\end{tabular}


process quality, product supply delivery and volume flexibility and to satisfy the variety of customer product demands. To achieve these types of competitive performance, in addition to the integration and collaboration of S1, the development of collaborative approaches (S2) and joint decision making (S3) will also be needed to improve integration and collaboration with suppliers. In stage 3, in addition to Q2, Q3, E1, E2, and L2, the competitive performance of Q1 (product quality and reliability), E3 (manufacturing lead time), L1 (volume flexibility), and L3 (product customization) should be achieved. In addition to satisfying the variety of customer demands, manufacturers need to provide the highest product quality, demonstrate a diversified production ability, shorten delivery, and achieve the highest flexibility production ability possible to satisfy different types of customers. To achieve these types of competitive performance, in addition to S1, S2, and S3, this third stage will expand the scope of integration and collaboration with customers by improving the sharing of information such as market demand or feedback (R1), developing collaborative approaches to establishing a close relationship with customers (R2), inviting partners from downstream to be joint decision makers (R3), and developing a coupling system to maintain relationships with customers (R4). In addition to the types of competitive performance of stage 3, cost performance needs to be achieved in stage 4 . In this stage, manufacturers need to improve integration and collaboration for all functional activities to achieve all types of competitive performance. However, this stage improves first. When everything appears to be stable, then manufacturers need to strengthen the integration and collaboration of all their functional activities to ensure that all types of competitive performance can be achieved and to further ensure that all customer demands can be satisfied.

\section{Discussion}

The analysis results of the case study proved that using the revised taxonomic approach can certainly solve the three problems outlined in the introduction, reminding and further guiding manufacturers to effectively improve their integration and collaboration. Based on precisely when manufacturers try to enter different markets, the analysis results can tell them how their integration and collaboration should be improved and through how many stages. In the first stage, the analysis results indicate which type of competitive performance is basic in relation to market qualification. The analysis results will remind manufacturers which types of integration and collaboration with regard to functional activities can ensure the achievement of basic competitive performance. Afterward, the analysis results indicate which types of competitive performance should be achieved in the next stages to expand their competitiveness. To achieve these types of competitive performance at every stage, the analysis results can guide manufacturers to understand which functional activities should be integrated and collaborated gradually in different stages.

Based on the above, this approach helps manufacturers avoid wasting large time costs to identify basic competitive performance and the order of competitive performance priorities. In addition, because the achievement of basic competitive performance symbolizes the satisfaction of basic demands, its achievement can help manufacturers obtain market qualifications. Additionally, when competitive performance is achieved and gradually deepened, the 
satisfaction of market demands is expanded. This means that the increases in profit will be stable. This outcome can certainly reduce partners' hesitancy with regard to risk sharing and their uncertainty with regard to obtaining profits. Thus, it can prevent partners' opportunistic behaviours and raise their intentions with regard to integration and collaboration. Finally, it can prevent the simultaneous integration and collaboration of all functional activities and further avoid the problem of a complicated resource distribution and heavy workloads.

However, how can the revised taxonomic approach solve the three problems outlined in the introduction and help manufacturers effectively improve their integration and collaboration? The success of this approach is due to the correlation analysis and within-cluster paired-sample t-tests. When the research uses the two-stage cluster analysis of the traditional taxonomic approach, the analysis results only classify the clusters. Although the number of improvement stages related to integration and collaboration can be inferred and find that the concept of phased phenomenon exists between clusters through the changes in the means of the observed variables, the traditional taxonomic approach cannot prove that the two-stage cluster analysis can become an improvement process for integration and collaboration. However, correlation analysis and within-cluster paired-sample t-tests can address this inability. Correlation analysis can be used to explore which functional activities should be integrated and collaborated in each stage. In addition, within-cluster paired-sample t-tests can be used to prove that the integration and collaboration of every stage are based on the previous stage to ensure gradual expansion. If the same methods are used to analyse the competitive performance of every stage, the findings can indicate which types of competitive performance should be achieved in every stage and prove that the expanding competitive performance of every stage is based on achieving the competitive performance of the previous stage. If the analysis results of competitive performance are combined with the analysis results of integration and collaboration improvement, the outcome can strengthen the inference for the process of improving integration and collaboration.

Finally, a similar revised analysis process was discussed by Xu et al. (2020). However, there is a fault that may reduce the precision of the analysis results. Xu et al. adopted a t-test to explore which functional activities in same cluster would be the focus of improvement. However, if the analysis results show that differences do not exist between the functional activities, as in $\mathrm{Xu}$ et al., then we believe that these functional activities may be jointly improved in same cluster. However, a t-test only explores the existence of differences. If the t-test results show no differences between the functional activities, then the results lack persuasion based on scientific principle to show that these functional activities may be jointly improved. If the analysis results of the jointly improved functional activities are in doubt, this may affect the analysis results of the phased improvements between the clusters. Based on the above, the current study adopts a correlation relationship analysis instead of a t-test analysis. Correlation analysis studies the correlation between two or more variables. If it is deemed that a functional activity is the activity in the cluster that has been mainly improved, and if this activity has a correlational relationship with another functional activity, then these two functional activities can be deemed as being the focus of improvement. In a statistical perspective, this result has a virtual meaning. Based on the results of the correlation relationship analysis, the results of the phased improvements between the clusters will be better and 
more precise than the results from the study of Xu et al. However, the research results of Xu et al. still have reference value.

\section{Conclusions}

Although integration and collaboration are considered critical factors in supply chain practice, improving integration and collaboration still encounters a dilemma that is ascribable to three problems, i.e., partners' opportunistic behaviours, the complicated resource distribution and heavy workloads, and large time costs. Based on these problems, this study attempted to develop an approach to solve these problems and further guide the improvement of integration and collaboration. The development of the approach was based on the traditional taxonomic approach; this study revised the traditional taxonomic approach and added some statistical methods to further develop it. The analysis process of this approach can be divided into five steps, and the analysis results can provide guidelines to guide the improvement of integration and collaboration in a phased manner. According to case of East Asia, the revised taxonomic approach certainly produces guidelines to help manufacturers well know how to improve integration and collaboration in a sequential manner.

Regarding academic implications, this study tried to analyse the revised feasibility and further develop a new approach based on the traditional taxonomic approach to improve integration and collaboration. Therefore, the approach is a theoretical breakthrough and provides a way for researchers to examine integration and collaboration improvement. Regarding practical implications, the revised taxonomic approach not only makes it possible to provide guidelines to help manufacturers know how to improve their integration and collaboration in a sequential manner but also makes it possible to increase the speed of market share expansion when entering a new market and to decrease the rate of failure in improving integration and collaboration. Thus, the revised taxonomic approach has greater practical implications and contributions.

However, the revised taxonomic approach still has a few limitations. First, if manufacturers cannot collect actual data on their competitors' experience in each market, it will be difficult for the revised taxonomic approach to provide guidelines for their integration and collaboration. Therefore, the effectiveness of the collected related data is a major challenge. Second, the revised taxonomic approach adds related statistical methods, including correlation analysis and within-cluster paired-sample t-tests, to the traditional taxonomic approach. However, why are these two methods applied? In this research, the algorithm is explained only through inference and the recognition of what is lacking. Based on the above, researchers may explore these factors more deeply in the future.

\section{Funding}

This work was supported by the National Natural Science Foundation of China (NSFC) under Grant 71872131. 


\section{Author contributions}

Ping-Kuo CHEN and YunYan LU conceived the study and were responsible for the design and development of the research concept. Ping-Kuo CHEN and YunYan LU were responsible for data collection and analysis. YunYan LU were responsible for data interpretation. PingKuo CHEN and YunYan LU wrote the first draft of the article.

\section{Disclosure statement}

The authors have no competing financial, professional, or personal interests from other parties that are related to the subject of this paper.

\section{References}

Alblas, A., \& Jayaram, J. (2015). Design resilience in the fuzzy front end (FFE) context: An empirical examination. International Journal of Production Research, 53(22), 6820-6838. https://doi.org/10.1080/00207543.2014.899718

Avelar-Sosa, L., García-Alcaraz, J. L., \& Maldonado-Macías, A. A. (2019). The importance of supply chains in global competitiveness. In Evaluation of supply chain performance (pp. 15-24). Springer. https://doi.org/10.1007/978-3-319-93876-9_2

Bai, X. J., \& Gao, Y. P. (2017, October). Purchasing strategy analysis based on the relative value of the purchasing material. In $3^{\text {rd }}$ Annual 2017 International Conference on Management Science and Engineering (MSE 2017). Atlantis Press. https://doi.org/10.2991/mse-17.2017.20

Barratt, M. (2004). Understanding the meaning of collaboration in the supply chain. Supply Chain Management: an International Journal, 9(1), 30-42. https://doi.org/10.1108/13598540410517566

Boer, H., \& Boer, H. (2019). Design-for-variety and operational performance. Journal of Manufacturing Technology Management, 30(2), 438-461. https://doi.org/10.1108/JMTM-03-2018-0065

Cao, Z., Huo, B., Li, Y., \& Zhao, X. (2015). Competition and supply chain integration: A taxonomy perspective. Industrial Management \& Data Systems, 115(5), 923-950. https://doi.org/10.1108/IMDS-10-2014-0315

Chen, P. K., Chou, F. D., Dai, X., \& Ye, Y. (2018). Development of a supply chain integration process. IEEE Access, 6, 40226-40244. https://doi.org/10.1109/ACCESS.2018.2856262

Dowlatshahi, S., \& Taham, F. (2009). The development of a conceptual framework for Just-In-Time implementation in SMEs. Production Planning and Control, 20(7), 611-621. https://doi.org/10.1080/09537280903034305

Echave, I., de los Santos, A., Garmendia, I., \& Gil, A. M. (2006, June). Tools and practices for the product innovation process in the company's network. In 2006 IEEE International Technology Management Conference (ICE) (pp. 1-8). IEEE. https://doi.org/10.1109/ICE.2006.7477045

Edmunds, P. (2015). Achieving a competitive supply chain network for a manufacturer. Journal of Manufacturing Technology Management, 26(5), 744-762. https://doi.org/10.1108/JMTM-01-2013-0004

Frohlich, M. T., \& Westbrook, R. (2001). Arcs of integration: An international study of supply chain strategies. Journal of Operations Management, 19(2), 185-200. https://doi.org/10.1016/S0272-6963(00)00055-3

Grant, N., Cadden, T., McIvor, R., \& Humphreys, P. (2013). A taxonomy of manufacturing strategies in manufacturing companies in Ireland. Journal of Manufacturing Technology Management, 24(4), 488-510. https://doi.org/10.1108/17410381311327378 
Huo, B., Gu, M., \& Wang, Z. (2018). Supply chain flexibility concepts, dimensions and outcomes: An organisational capability perspective. International Journal of Production Research, 56(17), 5883-5903. https://doi.org/10.1080/00207543.2018.1456694

Huo, B., Ye, Y., Zhao, X., \& Zhu, K. (2019). Supply chain quality integration: A taxonomy perspective. International Journal of Production Economics, 207, 236-246. https://doi.org/10.1016/j.ijpe.2016.05.004

Ye, Z., Ming, L., \& Meiging, Z. (2008, July). Coupling evaluation and optimization strategy of the Supply Chain System. In 2008 Chinese Control and Decision Conference (pp. 1156-1159). IEEE.

Yuen, K. F., \& Thai, V. (2017). Barriers to supply chain integration in the maritime logistics industry. Maritime Economics \& Logistics, 19(3), 551-572. https://doi.org/10.1057/mel.2016.10

Kasemsap, K. (2016). Fostering supply chain management in global business. In Handbook of research on global supply chain management (pp. 45-71). IGI Global.

https://doi.org/10.4018/978-1-4666-9639-6.ch003

Kathuria, R. (2000). Competitive priorities and managerial performance: A taxonomy of small manufacturers. Journal of Operations Management, 18(6), 627-641. https://doi.org/10.1016/S0272-6963(00)00042-5

Kumar, V., Holt, D., Ghobadian, A., \& Garza-Reyes, J. A. (2015). Developing green supply chain management taxonomy-based decision support system. International Journal of Production Research, 53(21), 6372-6389. https://doi.org/10.1080/00207543.2014.917215

Lee, A. B. S., Chan, F. T., \& Pu, X. (2018). Impact of supplier development on supplier's performance. Industrial Management \& Data Systems, 118(6), 1192-1208.

https://doi.org/10.1108/IMDS-05-2017-0229

Liu, C., Huo, B., Liu, S., \& Zhao, X. (2015). Effect of information sharing and process coordination on logistics outsourcing. Industrial Management \& Data Systems, 115(1), 41-63.

https://doi.org/10.1108/IMDS-08-2014-0233

McLaren, T., Head, M., \& Yuan, Y. (2002). Supply chain collaboration alternatives: Understanding the expected costs and benefits. Internet Research, 12(4), 348-364.

https://doi.org/10.1108/10662240210438416

Miller, J. G., \& Roth, A. V. (1994). A taxonomy of manufacturing strategies. Management Science, 40(3), 285-304. https://doi.org/10.1287/mnsc.40.3.285

Miltenburg, J. (2005). Manufacturing strategy: How to formulate and implement a winning plan. CRC Press. https://doi.org/10.4324/9781482278392

Mora-Monge, C. A., Hong, P., Tran, O., \& Park, K. (2010). Electronic commerce applications for supply chain integration and competitive capabilities. Benchmarking: An International Journal, 17(4), 539-560. https://doi.org/10.1108/14635771011060585

Nguyen, M. A. T., Lei, H., Vu, K. D., \& Le, P. B. (2019). The role of cognitive proximity on supply chain collaboration for radical and incremental innovation: A study of a transition economy. Journal of Business \& Industrial Marketing, 34(3), 591-604. https://doi.org/10.1108/JBIM-07-2017-0163

Nickerson, R. C., Muntermann, J., \& Isaac, H. (2009). The emergence of a new form of IS offshore enterprise - The modern heterarchy. ECIS 2009 Proceedings.

Niu, B., Chan, F. T., Xie, T., \& Liu, Y. (2017). Guided chemotaxis-based bacterial colony algorithm for three-echelon supply chain optimisation. International Journal of Computer Integrated Manufacturing, 30(2-3), 305-319. https://doi.org/10.1080/0951192X.2016.1145809

Oh, S., Ryu, Y. U., \& Yang, H. (2016, January). Supply chain capabilities and information technology characteristics: Interaction effects on firm performance. In $201649^{\text {th }}$ Hawaii International Conference on System Sciences (HICSS) (pp. 1417-1425). IEEE. https://doi.org/10.1109/HICSS.2016.179

Paulraj, A., Chen, I. J., \& Lado, A. A. (2012). An empirical taxonomy of supply chain management practices. Journal of Business Logistics, 33(3), 227-244. https://doi.org/10.1111/j.0000-0000.2012.01046.x 
Plott, C., Roll, R., Seo, H., \& Zhao, H. (2019). Tick size, price grids and market performance: Stable matches as a model of market dynamics and equilibrium. Games and Economic Behavior, 118, 7-28. https://doi.org/10.1016/j.geb.2019.08.004

Prajogo, D., Oke, A., \& Olhager, J. (2016). Supply chain processes: Linking supply logistics integration, supply performance, lean processes and competitive performance. International Journal of Operations \& Production Management, 36(2), 220-238. https://doi.org/10.1108/IJOPM-03-2014-0129

Rakovska, M. A., \& Stratieva, S. V. (2018, January). A taxonomy of healthcare supply chain management practices. Supply Chain Forum: An International Journal, 19(1), 4-24. https://doi.org/10.1080/16258312.2017.1395276

Sangari, M. S., Razmi, J., \& Gunasekaran, A. (2016). Critical factors for achieving supply chain agility: Towards a comprehensive taxonomy. International Journal of Industrial and Systems Engineering, 23(3), 290-310. https://doi.org/10.1504/IJISE.2016.076870

Schoenherr, T., \& Swink, M. (2012). Revisiting the arcs of integration: Cross-validations and extensions. Journal of Operations Management, 30(1-2), 99-115. https://doi.org/10.1016/j.jom.2011.09.001

Schlegelmilch, B. B. (2016). Global supply chains and distribution networks. In Global Marketing Strategy (pp. 129-151). Springer. https://doi.org/10.1007/978-3-319-26279-6_7

Shin, J., \& Lee, J. H. (2015). MDP formulation and solution algorithms for inventory management with multiple suppliers and supply and demand uncertainty. Computer Aided Chemical Engineering, 37, 1907-1912. https://doi.org/10.1016/B978-0-444-63576-1.50012-1

Soosay, C. A., \& Hyland, P. (2015). A decade of supply chain collaboration and directions for future research. Supply Chain Management: An International Journal, 20(6), 613-630. https://doi.org/10.1108/SCM-06-2015-0217

Sundram, V. P. K., Bahrin, A. S., Abdul Munir, Z. B., \& Zolait, A. H. (2018). The effect of supply chain information management and information system infrastructure: The mediating role of supply chain integration towards manufacturing performance in Malaysia. Journal of Enterprise Information Management, 31(5), 751-770. https://doi.org/10.1108/JEIM-06-2017-0084

Tavana, M., Shabani, A., \& Singh, R. (2019). The impact of interwoven integration practices on supply chain value addition and firm performance. Journal of Industrial Engineering International, 15, 1-13. https://doi.org/10.1007/s40092-019-0316-8

Wang, H., Mastragostino, R., \& Swartz, C. L. (2016). Flexibility analysis of process supply chain networks. Computers \& Chemical Engineering, 84, 409-421. https://doi.org/10.1016/j.compchemeng.2015.07.016

Xu, W., Chen, P. K., \& Ye, Y. (2020). Effective improvement in supply chain integration through a revised taxonomy. In IEEE Engineering Management Review. https://doi.org/10.1109/EMR.2020.2968008

Zhao, X., Sum, C. C., Qi, Y., Zhang, H., \& Lee, T. S. (2006). A taxonomy of manufacturing strategies in China. Journal of Operations Management, 24(5), 621-636. https://doi.org/10.1016/j.jom.2005.07.003

Zhao, X., Xie, J., \& Lau, R. S. M. (2001). Improving the supply chain performance: Use of forecasting models versus early order commitments. International Journal of Production Research, 39(17), 3923-3939. https://doi.org/10.1080/00207540110072236 